\title{
The Formalization of the Knowledge Management in the Managerial Approach in the Algerian Firms: Case of the Territorial Direction of Algeria Telecom of Tlemcen
}

\author{
Abdelheq Lachachi \\ Faculté des sciences économiques, sciences de gestion et sciences commerciales \\ Université Abou bekr Belkaid - Tlemcen \\ abdelheq.lachachi@mail.univ-tlemcen.dz
}

\begin{abstract}
Abdelatif Kerzabi
Faculté des sciences économiques, sciences de gestion et sciences commerciales Université Abou bekr Belkaid - Tlemcen Kerzabi57@gmail.com

Mustapha Houhou

Faculté des sciences économiques, sciences de gestion et sciences commerciales Université Abou bekr Belkaid - Tlemcen mustaphahouhou@yahoo.fr
\end{abstract}

\section{Doi:10.5901/mjss.2013.v4n6p191}

\begin{abstract}
In this article we treat the problems of the management of knowledge in the managerial approach, i.e., how the organizations manage its knowledge? While being based on the theory of resources to identify knowledge like a strategic resource, our aim is to propose a model of the management of knowledge which is based on the combination between the processes of the management of knowledge (creation, storage, the share, the use and the evaluation) and the factors personal (ambition, the behaviour and leadership) and organisational (strategy, vision, culture and the structure) with the contribution of information and communication technologies in order to acquire the competitive advantage. A case study was carried out in the territorial direction of Algérie Télécom of Tlemcen to show the importance of the management of knowledge in the organization.
\end{abstract}

Keywords: knowledge, knowledge management, theory of resources, processes, managerial approach, Algérie Télécom.

\section{Introduction}

In an economy characterized by complexity and the permanent change, the only source of the durable competitive advantage is knowledge and the firms which succeed are those which create new knowledge constantly.

Several works regarded knowledge as an economic capital, a factor of productivity, stability and a competitive asset. The whole of knowledge of the knowledge constitutes its wealth, but the majority of vital knowledge for the firm is tacit; they are in the subconscious level of the individual, and so, they are difficult to articulate and share with the others. Therefore, the function which consists in "managing" knowledge proves primordial.

The knowledge management is a fundamental subject for the firms. It knew an importance growing during these three last decades. However; the reality in Algerian enterprises is still far from being satisfactory.

Managing knowledge, is first to create it, acquire it, store it, share it, use and evaluate it.

The knowledge management is a discipline in constitution which is borrowed from varied fields: economy, management, psychology, sociology, sciences and information technology, education science ...

The objective of the knowledge management is of setting up of devices (organization, methods and tools) which develop the stock of knowledge that any social organization (and more specifically an enterprise) accumulate during its life cycle.

The stakes for the firms are strong: productivity, competitiveness, creativity, prosperity and perenniality... 


\subsection{Research questions:}

Many researches have shown that there exist two approaches of knowledge management; the managerial approach which puts stress on personalization of knowledge and technological approach which emphasizes the codification of knowledge.

It is noted that the model dominating is the technological approach because the evolution of information and communication technology largely contributed to the development of this model. In counterpart, it is noted that the managerial approach is little treated and badly formalized.

Therefore, our key question is the following: taking into account the managerial approach, how do the organizations manage their knowledge? more specifically: how does the Algerian organizations manage their knowledge?.

\subsection{Hypothesis:}

The hypotheses which our study will be based on are the following:

A. The strategic management of knowledge leans on the personal relations and the interactions between them in order to increase the creation and the sharing of new knowledge.

B. In the managerial approach, the strategic management of knowledge is based on the combination between the processes of knowledge management, the personal factors and the organizational factors with the contribution of information and communication technology in order to acquire the competitive advantage.

\section{Literature Review}

Knowledge is the most important concept of the management which emerged in the thirty last years. It is regarded as primordial assets of the organization, because today the most important resource for the organization is no more the land, neither the work, nor the capital, but rather the knowledge. Many researchers are regarded as the only source of the competitive advantage. Consequently, the continuity of the organization in a complex and changeable environment depends on its faculty to manage its stock of knowledge efficiently.

The theory of the resources (called "Resource based-view" in the Anglo-Saxon countries) finds its origins in work of Bernard (1985), Selznick (1957) and Schandler (1957) on the basis of strategic management. This work concerned on the capacities of the firm to use these resources and the creation of the economic performance. Indeed, Edith. T. Penrose is generally recognized like the pioneer author of this theory. In her work "The theory of growth of the firm" in 1959, Penrose put stress on the importance of the material and immaterial resources to explain the existence and the growth of the firm (Barabel and al, 2008, p 93), it is not when 1984 that the approach takes officially the name of Resource Based-view with the authors: Werneflet (1984), Dierickx and coll (1989) and Barney (1991). The theory of resources regards the firm as "a whole of the resources, competences and capacities" (Fillol, 2006, p 26). According to Barney (1991), the resources of the firm include the whole of the organizational processes, the attributes and knowledge (Guedda, 2008, p 18). Werneflet defines the resources as "the whole of tangible assets (financial physical resources) and intangible (knowledge, patents, marks)". According to Barney, there exist three categories of resources (physical, human, organizational), and for Grant, there are six varieties of resource which are: financial resources, physical, human, technological, organizational and the reputation.

Competences are the capacities of the firm to assemble resources in order to realize a task or an activity. Competences of a firm are specific and thus nontransferable (Baudry, 2003, p 29).

\subsection{Data, information and knowledge:}

The concept of knowledge is one of the most used concepts in the field of literature of knowledge management, its definition is difficult because knowledge, information and data are often interchangeable, and to raise this ambiguity we shall define these concepts.

2.1.1 Data: is a discrete fact, brut (Prax, 2003, p 60), it represents observations or facts except context which is not, therefore, directly significant, i.e. it does not have sense in itself (Nada and al, 2003, p 76), it has objective and 
quantitative or qualitative nature (Aliouat, 2005, p 62), it can be recorded, captured, manipulated or searched for (ferreted out). The data can be extracted for useful information (Kipling, 2007, p 05).

2.1.2 Information: is a data treated by processes of condensation, of contextualisation, of calculation, of categorization and/or correction, and which carries a certain signification.

2.1.3 Knowledge: is a large and abstract concept, multi-facets and polysmous. It is the object of the knowledge management, and it is a new field of research in term of formalization and theorization. Knowledge is defined as: "Information made exigible from a way in which the value adds to the firm" (Richard and al, 2006, p 20), or "a justified personal belief which increases the capacity of an individual to take an effective measure" (Alavi and Leidner, 2001, p 109).

2.1.4 Wisdom: several researchers include wisdom in their definitions of knowledge. In this vein; wisdom is defined as "the use of accumulated knowledge" or "an advanced level of the knowledge which comes with the experience and the use of accumulated knowledge" (Kipling, 2007, p 05).

These concepts form the hierarchy (pyramid) of knowledge (figure 1).

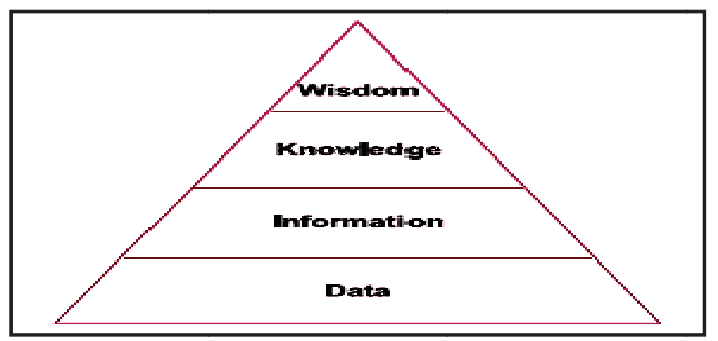

Figure 1: The hierarchy (the pyramid) of knowledge (Faucher and al, 2008, p. 07)

\subsection{The classification of knowledge:}

In the literature of knowledge management, the distinction most frequently used is between tacit and explicit knowledge (epistemological dimension). Moreover, there exists the ontological dimension which represents the various levels of knowledge: individual and collective knowledge.

\subsubsection{Tacit knowledge:}

Tacit knowledge can be defined as a knowledge which is personal, specific to a given context. It is rooted in a subconscious level and so it is difficult to formalize, communicate and share with the others (Dietrich and Cazal, 2003, p. 14). It is characterized by the expression of Polayni: "we know always more than we can say" (Foray, 2004, p. 46).

According to Nonaka and Konno (1998) tacit knowledge is composed of two dimensions: cognitive and technical. Cognitive dimension relates to knowledge makes it possible to put in action objects. They are the beliefs, the paradigms, the values, the diagrams and the mental models and the view points. Technical dimension relates to know-how, trades (practices) and qualifications which apply to a specific context (Nonaka and Konno, 1998, p 42).

\subsubsection{Explicit knowledge:}

Explicit knowledge is the knowledge which is codified and transmitted in a formal and systematic language (Kipling, 2007, p 05), it is articulated, formalized, objective, accessible and is presented in a form of documents, databases, symbols, graphs and handbooks.

Tacit knowledge is extremely important in the organization because people acquire this knowledge by activity of (re) creation and organization of their own experiences. In this respect, Beijerse represents knowledge like an iceberg and explicit knowledge is just the emerged part of the iceberg (see the figure 02). 


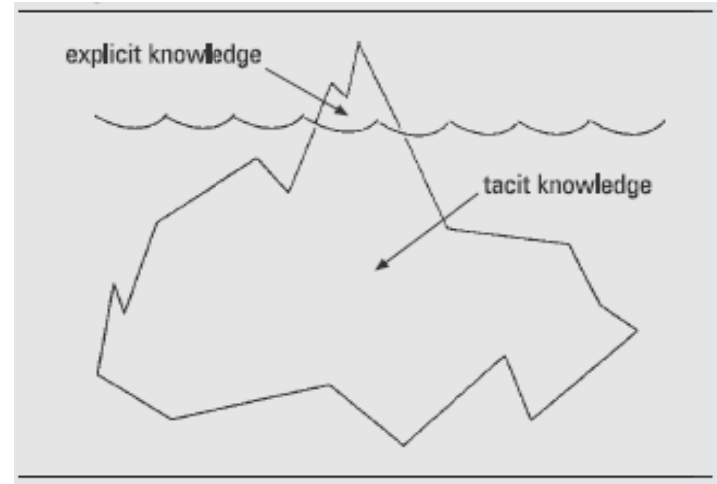

Figure 02: Representation of tacit and explicit knowledge (Beijerse, 1999, p. 100)

\subsubsection{Individual knowledge:}

Individual knowledge represents the cognitive collection of an individual (Marchand, 2005, p. 16), it is also defined as the whole of the beliefs of an individual on the relations of cause for the effect between phenomena (Perrin, $p$ 06), and it is held and controlled by the individual (Sammer and al, 2003, p 03).

\subsubsection{Collective knowledge:}

Collective knowledge is:

"The knowledge which makes it possible of a group of people to realize complex tasks and specific to the firm, and which would be difficult to imitate".

"The knowledge attached to a group acting in a given professional framework" (Bordères and Panisse, 2003, p. 02).

"The knowledge which is adapted in a specific environment (like the firm), it includes the individual knowledge which reaches only its full potential once combined with the others (e.g a football player plays better in the group than individual) (Sammer and al, 2003, p. 03).

We can schematize the types of knowledge (tacit/explicit and individual/collective) in the following figure:

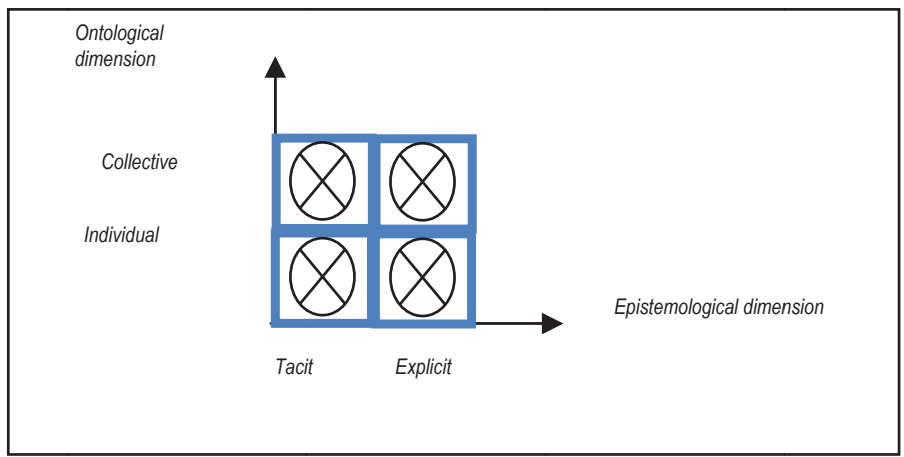

Figure 03: Types of knowledge (own source)

\section{Knowledge Management}

Knowledge management is a topicality theme, it appeared in the years 1990's (Aliouat, 2005, p 62), which was the subject of several researches. He regards the knowledge of the firm as an inheritance and that for this reason it must be 
managed. It was noted that there exists often a conflict between the managerial approach and the technological approach, in other words between an approach which puts the stress on "the personalization of knowledge" and that which puts the stress on "the coding of knowledge" (Hansen and al, 2003, p. 119).

The managerial approach or (the human resources approach) was developed by the consultants (Davenport, Sveiby, Prax, Stewart, Wiig and Nonaka). This approach emphasizes the existence of a strong bond between knowledge and the person who has created and carried it (Benabou, 2008, p 137; Prax, 2003, p. 63).

According to Hamilton, the knowledge management is defined like a process of creation, of acquisition, transfer and of use of knowledge with the aim of improving the output of the organization; it is related to the two types of activity: a) the activities by which we try to document and to adapt individual knowledge and those being used to diffuse this knowledge within the organization

b) The activities which facilitate the human exchanges, within the framework of which we share a knowledge not codified (Ben amor, p. 07).

For Scarbrough and al, the knowledge management is defined like a process or practical aiming at creation, acquisition, share and use of knowledge in order to authorize the learning and the performance of the organizations (Gaha and Mansour, p. 1903).

From these definitions, we can release a certain number of important characteristics relating to the idea of the knowledge management. It is about a strategy:

Aiming at formally structuring the explicit and tacit assets of knowledge of an organization to create the value;

In bond with the strategic directions of an organization and its needs for innovation and improvement for competitiveness;

Supported by a technological and organizational infrastructure;

Organized around the processes of knowledge management (create, store, share, use...);

Where the human is the first place of interaction and creation of knowledge.

\section{Strategic Plannings of the Knowledge Management}

We can distinguish two strategies from the knowledge management that are strongly different.

\subsection{Strategy of personalization:}

The strategy of personalization concentrates on the development of the networks to connect people so that tacit knowledge can be shared. It focuses on the dialog between the individuals through an approach "person to person" (Roland, 2004, p. 23).

Any knowledge that have not been codified - and which could probably not be circulates by the means of meetings of brainstorming and individual conversations (Hansen et al., 2003, p. 123).

The investment is based on the realization of the interpersonal networks (where knowledge is shared not only face to face but also by telephone and via videoconference) and the development of a culture of co-operation and share. . The aim of this strategy is to facilitate the learning through the share of knowledge (Roland, 2004, p. 23).

This strategy is chosen by the companies which are generally confronted with single problems (Foray, 2004, p. 96).

\subsection{Strategy of codification:}

This strategy is intended to collect, codify and store explicit knowledge in the database to make available to all the employees from the organization. It is strongly based on communication and information technologies. Knowledge is codified through an approach "person to document"; knowledge is extracted from the person who developed it, it is made independent of this person and it is re-used for different objectives (Hansen et al., 2003, p. 121).

This strategy is used by the firms which are permanently confronted with the same type of problem of their customers and whose objective is to provide a fast service and to avoid reinventing the wheel (Foray, 2004, p. 95-96).

\section{Knowledge Management Processes}

Knowledge management processes are a paramount function of this one, certain authors represent them as the heart of 
the management of knowledge (Byounggu, 2002, p 18). Table $n^{\circ} 01$ recapitulates the different models of knowledge management processes:

There are many models of knowledge management processes which describe the relation of the principal processes from three steps (produce, codify and transfer) to seven steps (create, acquire, identify, adapt, organize, distribute, apply) (King, 2009, p 06).

Indeed, there is not a consensus on a standard model of knowledge management processes but almost all the models focus on five basic processes: creation, storage, share, the use and the evaluation of knowledge.

The function of the knowledge management in the firm is to manage these processes and to develop methods and systems for supporting them and motivating the individuals to take part in these processes (King, 2009, p. 06).

\begin{tabular}{|l|l|}
\hline Author & KM Process \\
\hline Anderson \& APQC [1996] & Applying, Sharing, Creating, Identifying, Collecting, Adapting, Organizing \\
\hline Arthur D. Little [1998] & Acquisition and creation, Saving, Dissemination, Use \\
\hline Delphi [1998] & Capturing, Sharing, Leveraging, Feeding \\
\hline Demarest [1997] & Construction, Embodiment, Dissemination, Use \\
\hline Ernst \& Young [1998] & Planning, Acquiring, Applying, Assessing \\
\hline Jang \& Lee [1998] & $\begin{array}{l}\text { Knowledge acquisition, Schema codification, Knowledge codification, Knowledge retrieval, } \\
\text { Knowledge embedding, Problem analysis, Problem solving, Knowledge shaping }\end{array}$ \\
\hline KPMG [1998] & $\begin{array}{l}\text { Creation, Application, Exploitation, Sharing and dissemination, Encapsulation, Sourcing, } \\
\text { Learning }\end{array}$ \\
\hline Lee \& Kim [2001a] & Accumulation (acquisition and creation), Integration, Reconfiguration \\
\hline Leonard-Barton [1995] & Problem solving, Implementing and integrating, Experimenting, Importing \\
\hline Nevis et al [1995] & Acquisition, Dissemination, Utilization \\
\hline Nonaka \& Takeuchi [1995] & $\begin{array}{l}\text { Sharing tacit knowledge, Creating concepts, Justifying concepts, } \\
\text { Building a archetype, Cross leveling knowledge }\end{array}$ \\
\hline Pan \& Scarbrough [1998] & Generation, Processing, Storage, Dissemination, Use/reuse \\
\hline Pentland [1995] & Construction, Organization, Distribution \\
\hline Probst [1998] & $\begin{array}{l}\text { Knowledge goal, Identification, Acquisition, Development, Distribution, Preservation, Use, } \\
\text { Measurement }\end{array}$ \\
\hline
\end{tabular}

Table $n^{\circ}$ 01: Knowledge Management Processes

(Byounggu, 2002, p. 19)

\subsection{The creation of knowledge:}

The creation of knowledge can be defined as "a development process of new knowledge". Great points concerning the creation of knowledge referring to the four modes of Nonaka (Socialization, Combination, Externalisation, Internalisation). Organisational knowledge can be created via the organisational learning processes and the routines (Nevo et al., 2007, p. 235).

The creation of knowledge includes/understands also the acquisition of knowledge. It implies the identification and the assimilation of potentially valid knowledge, often of the outside of the firm.

The acquisition of knowledge focuses on some processes to acquire the knowledge of the internal sources (as on the Intranet), or provisioning (adding an individual which has the knowledge wished with the firm) (King, 2009, p 08).

\subsection{The storage of knowledge:}

After new knowledge is created or acquired, of the mechanisms of management of knowledge should be placed to memorize them in order to maximize its long-term impact and its reutilisability.

Knowledge created must be stored and filed in the organisational memory. The organisational memory can be defined as a whole of devices of conservation of knowledge, such as the people and the documents which collect, store and allowé2\& access the experiment of the firm (Nevo et al., 2007, p 236).

The organisational memory includes knowledge resident in the various forms including written documentation, the information structured and stored in the electronic databases and the tacit knowledge stored in the spirits of the individuals of the firm and the processes of organization. 


\subsection{The share of knowledge:}

The division of knowledge is "the process of exchange of knowledge between the individuals in the firm, it is a bilateral interaction" (Rossion, 2008, p 50). The firm must establish a culture which supports this division of knowledge. The community of practice is a method in which knowledge is shared perfectly in the group. The share of knowledge includes also the transfer of knowledge which is a unilateral interaction.

\subsection{The application of knowledge:}

Knowledge must be applied to solve the problems, and to make better decisions (Hsia et al., 2006, p 15) and also to acquire the competitive advantage (Sammour et al., 2008, p 469).

\subsection{The evaluation of knowledge:}

Knowledge must pass by the evaluation to check that it is appropriate and precise to the definite situations (Sammour et al., 2008, p 469).

These processes do not represent a monolithic unit, but an inter-connected and interlaced unit. We can summarize these processes in the figure $n^{\circ} 04$.

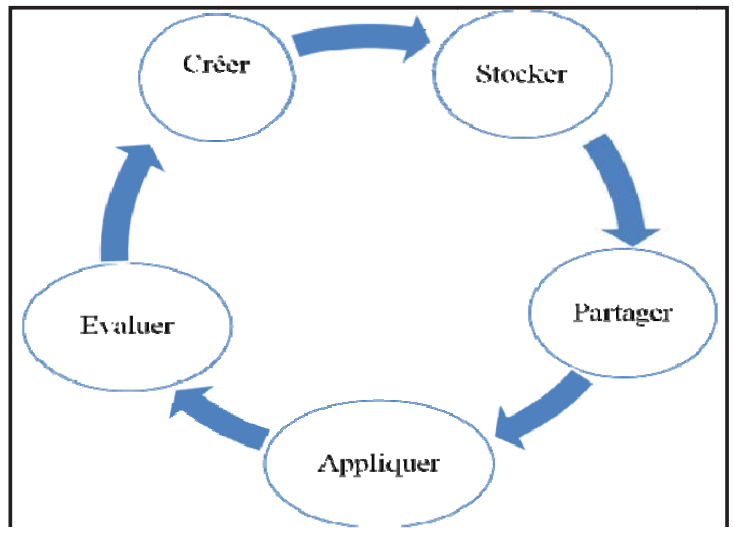

Figure $\mathrm{n}^{\circ} 04$ : knowledge management processes

(own Source)

\section{The Framework (the Infrastructure) of the Management of Knowledge:}

The organization must support the processes of the management of knowledge while introducing and by cultivating the personal and organisational factors which stimulate these processes.

These factors constitute a framework (or an infrastructure) which make the management of knowledge efficient and effective (Salim et al., 2005, p 08) and make it possible the organization to effectively use its limited resources, to reduce the use of the hand, the material and time, and can carry out the results envisaged (Yeh et al., 2006, p 794).

The framework of the management of knowledge is a collection of elements (or factors) functioning together in variable combinations like a system to support the capital of knowledge of an organization and to ensure the performance and the training for a durable evolution (Gorelick and Tantawy-Monsou, 2005, p 126).

Several researches identify various factors; table $n^{\circ} 02$ summarizes these factors.

We can notice that there is a consensus on three main factors which are: individuals, processes and technologies of information and communication.

According to European Committee for Standardization (CEN), we will divide these factors into two parts: 


\subsection{Personal factors}

There exist key aspects concerning the individuals where the organizations which want to introduce the management of knowledge must establish and/or develop.

\subsubsection{The ambition :}

The individual and collective ambitions are a factor by which the individuals are motivated to take part in the various processes of the management of knowledge because there is part of shared knowledge which is on a purely voluntary basis (CEN, 2004, p 12).

\subsubsection{The behaviour:}

Since knowledge is related to the individuals, the effective development, storage, share and the use of knowledge depend on the individuals who can and want to do them. This means that they must be conscious of the relevance of knowledge, the various processes and the tools available. Therefore, the organization should stimulate the suitable behaviours of knowledge. These behaviours can sometimes be influenced by various external measurements such as the rewards and promotions or the recognition, but also internal measurements, the individuals should want to develop and influence the assets of knowledge. Other factors influence the behaviour like the personal values and beliefs and the degree of control in an organization (CEN, 2004, p 12).

\subsubsection{Leadership:}

The management of knowledge is an important function of the leader, because the degree of supports top management (executives and the services chiefs as well) determines the success or the failure of the management of knowledge. The behaviour of the leader can facilitate the transmission of knowledge by supporting the share of knowledge which influences the effectiveness of the organization.

Lakshman (2007) suggests that the role of the leader in the management of knowledge starts with the awakening of the leader to the importance of the management of knowledge in the performance of the organization. This awakening must appear on two dimensions: the intern and the external one. Internally, the awakening appears by the establishment of the two approaches technological and socio-cognitive of the management of knowledge, and outside, it concentrates on the customer (Lakshman, 2009, p 340-344).

\subsection{Organisational factors:}

The organizational factors are:

\subsubsection{Mission, vision and strategy:}

The mission describes why the organization wants to be implied in certain activities, the vision returns clarifies what it wants to be in the future and the strategy explains how this should be accomplished (CEN, 2004, p 15).

\subsubsection{Organisational culture:}

Lemken et al. (2000) describe the organisational culture like a "amount of shared philosophies, claims, values, hopes, attitudes and standards which link the whole of the organization" (Oliver and Kandadi, 2006, p 23).

It is also defined as "a combination of values, beliefs, models of behaviour and emblems. It represents the system of value of the organization which will have become the standard of the behaviour of the employees" (Yeh et al., 2006, p 797).

\subsection{The organizational structure:}

The organisational structures can block or facilitate the change. Some structures such as structures of networks or matrix 
could be more bearable than the hierarchical structures which are supported by more rigid organisational procedures (CEN, 2004, p 15), the repetitions of capacities and the preset roles can be a barrier with the execution of best practices. The large organizations, which are more complex, count of advantage on tacit routines to store knowledge.

Davenport and Prusak (1998) indicate that the maximum size of an organization for a management of knowledge optimal is approximately two to three hundred members (Simard and Rice, p 06-07).

\subsection{Information and communication technologies:}

Information and communication technologies are often regarded as a major element of the management of knowledge (Dubois and Wilkerson, 2008, p 24-25).

Information and communication technologies can allow the fast search, the access and the recovery of knowledge and information, and can also support collaboration and the communication between the members of the organization. They support the processes of the management of knowledge in the organization.

Information and communication technologies can help the management of knowledge in two main roads:

They provide the means so that the individuals organize, store and find knowledge explicit and information as in the electronic bookstores or the databases of the best practices. They connect between the individuals so that they can share tacit knowledge (NHS and Of Brown, 2005, p 59).

We can recapitulate the framework of the management of knowledge as well as the processes in the figure $\mathrm{n}^{\circ} 05$.

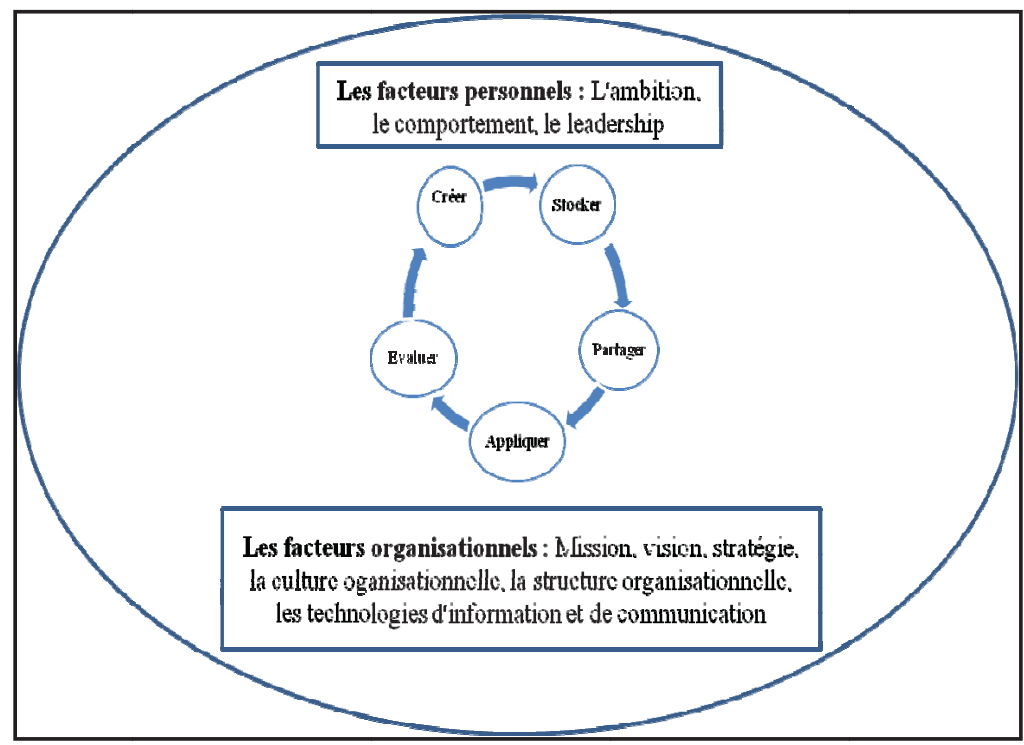

Figure $\mathrm{n}^{\circ} 05$ : The framework of the management of knowledge (own Source)

\section{The Case of the Territorial Direction of Algerie Telecom of Tlemcen}

To show the importance of management of knowledge in the organizations, we carry out a study within Algérie Telecom, and more precisely in its territorial direction of telecommunications of Tlemcen.

Presentation of Algerie Telecom:

Algérie Télécom is a joint stock company with public capital SPA, operative on the market of the networks and electronic communication services. It enters officially in activity starting from January 1st, 2003 and employment 21321 employees.

The major activity of Algeria Telecom is of: 
- To provide telecommunication services allowing the transport and the exchange of the voting right, written messages, digital data, audio-visual information...;

- To develop, exploit and manage the public networks and private telecommunications

- To establish, exploit and manage the interconnections with all the network operators; added:

Algérie Télécom is organized in divisions, central and regional directions, to this structure two subsidiaries are

- Mobile (Mobilis);

- $\quad$ Space Telecommunications (RevSat);

\subsection{The field of the study:}

The territorial direction of telecommunications of Tlemcen manages four Operational Units of Telecommunications (UOT) which are: Tlemcen, Sidi Bel Abbès, Saida and Nâama and also the seat of the territorial management of telecommunications of Tlemcen.

We used a questionnaire which comprises 38 questions in 8 axes carrying about the elements of our research, and it ends in two open-ended questions on waitings and the points of view relating to the application of the management of knowledge, and for the information processing, we used software SPSS version 11.

\subsubsection{Axe 01: The satisfaction of the management of knowledge and tacit and explicit orientation}

\begin{tabular}{|l|c|c|c|c|c|}
\hline & $\mathbf{N}$ & Min & Max & Mean & Std. Deviation \\
\hline Satisfaction of the management of knowledge & 123 & 1 & 3 & 1.67 & 0.671 \\
\hline Explicit knowledge & 123 & 1 & 2 & 1.52 & 0.502 \\
\hline Interaction & 123 & 1 & 2 & 1.53 & 0.501 \\
\hline Meetings & 123 & 1 & 2 & 1.47 & 0.501 \\
\hline Tacit knowledge & 123 & 1 & 2 & 1.52 & 0.502 \\
\hline Valid N (listwise) & 123 & & & & \\
\hline
\end{tabular}

Table $n^{\circ}$ 03: Axe 01: The satisfaction of the management of knowledge and tacit and explicit orientation

We notice that the averages of all the questions are less than 2 (the general average) between 1,47 and 1,67, therefore we can conclude that the employees are not satisfied with the management of knowledge in the firm, as it does not have their means which can store explicit knowledge. Moreover, there do not exist social interactions between the employees.

\subsubsection{Axe02: The creation and the share of knowledge}

\begin{tabular}{|l|c|c|c|c|c|}
\hline & N & Min & Max & Mean & Std. Deviation \\
\hline Creation and acquisition & 123 & 1 & 3 & 2.46 & 0.681 \\
\hline Use & 123 & 1 & 3 & 2.23 & 0.687 \\
\hline vision & 123 & 1 & 3 & 2.20 & 0.796 \\
\hline Share & 123 & 1 & 3 & 2.54 & 0.681 \\
\hline Share of information & 123 & 1 & 3 & 2.47 & 0.717 \\
\hline Direct contact & 123 & 1 & 3 & 2.30 & 0.757 \\
\hline Evaluation and transfer & 123 & 1 & 3 & 1.97 & 0.735 \\
\hline Valid N (list wise) & 123 & & & & \\
\hline
\end{tabular}

Table $n^{\circ}$ 04: Axe 02: The creation and the share of knowledge

We observe that the majority of the averages of the questions are more than 2, that wants to say that the employees (and even the firm) are able to create and acquire new knowledge and even to use them and share them in direct contact (face-to-face) except the question of the evaluation (the average is 1,97 and the deviation is of 0,735) where the informants are not satisfied with the evaluation of knowledge ;that is to say, there are no methods which make it possible to evaluate knowledge. 
7.1.3 Axe 03: The organisational learning

\begin{tabular}{|l|c|c|c|c|c|}
\hline & N & Min & Max & Mean & Std. Deviation \\
\hline Experience & 123 & 1 & 3 & 2.18 & 0.758 \\
\hline Learning by experience & 123 & 1 & 3 & 2.19 & 0.682 \\
\hline Learning by the errors & 123 & 1 & 3 & 2.44 & 0.667 \\
\hline Valid N (listwise) & 123 & & & & \\
\hline
\end{tabular}

Table $\mathrm{n}^{\circ}$ 05: Axe 03: The organisational learning

We observe that the averages of the questions are more average 2, which means that the employees agree on the importance of the training on the level of the organization, some is individual, collective or organisational.

7.1.4 Axe 04: Culture, community of practice and leadership

\begin{tabular}{|l|c|c|c|c|c|}
\hline & N & Min & Max & Mean & Std. Deviation \\
\hline The climate (culture) & 123 & 1 & 3 & 2.19 & 0.728 \\
\hline Membership & 123 & 1 & 3 & 1.99 & 0.773 \\
\hline Work groups & 123 & 1 & 3 & 2.07 & 0.791 \\
\hline Participation of the solutions & 123 & 1 & 3 & 1.88 & 0.795 \\
\hline Leadership & 123 & 1 & 3 & 2.17 & 0.776 \\
\hline Valid N (listwise) & 123 & & & & \\
\hline
\end{tabular}

Table $\mathrm{n}^{\circ}$ 06: Axe 04: Culture, community of practice and leadership

We notice that there is a variation of the averages which are between 1,88 and 2,19 with a deviation (which is large) between 0,773 and 0,791 , that means that there is not a climate which supports the division of knowledge on the level of the organization in general as there is no participation in the searching for the solutions in the organization.

\subsubsection{Axe 05: Trust}

\begin{tabular}{|l|c|c|c|c|c|}
\hline & N & Min & Max & Mean & Std. Deviation \\
\hline Trust & 123 & 1 & 3 & 2.04 & 0.804 \\
\hline Common vision & 123 & 1 & 3 & 1.94 & 0.728 \\
\hline Valid N (listwise) & 123 & & & & \\
\hline
\end{tabular}

Table $n^{\circ}$ 06: Axe 05: Trust

We notice that the average of the first question is more than 2 with a deviation of 0,804 , which means that there exists a climate of trust between the employees, but this climate does not translate the existence of a common vision in the organization (the average is of 1,94 and the deviation is of 0,728 ).

7.1.6 Axe 06: The organizational structure

\begin{tabular}{|l|c|c|c|c|c|}
\hline & $\mathbf{N}$ & Min & Max & Mean & Std. Deviation \\
\hline The organisational structure & 123 & 1 & 3 & 2.18 & 0.758 \\
\hline Harmonization & 123 & 1 & 3 & 1.98 & 0.746 \\
\hline The bidirectional communication & 123 & 1 & 3 & 1.96 & 0.793 \\
\hline Valid N (listwise) & 123 & & & & \\
\hline
\end{tabular}

Table $n^{\circ}$ 07: Axe 06: The organisational structure

We note that the first question has an average of 2,18 which is more than 2, that means that the structure of the organization supports the realization of the tasks through collective work, and it should be noted that the organization is 
reorganized to be more powerful, but this structure does not represent the harmonization between the various hierarchical levels (the average 1,98 and deviation 0,746 ) and the effectiveness of the bidirectional communication (the average 1,96 and deviation 0,793 ).

\subsubsection{Axe 07: Organisational memory}

\begin{tabular}{|l|c|c|c|c|c|}
\hline & $\mathbf{N}$ & Min & Max & Mean & Std. Deviation \\
\hline The routine & 123 & 1 & 3 & 2.13 & 0.809 \\
\hline The availability of knowledge & 123 & 1 & 3 & 1.98 & 0.746 \\
\hline The access to information & 123 & 1 & 3 & 2.07 & 0.791 \\
\hline Valid N (listwise) & 123 & & & & \\
\hline
\end{tabular}

Table $n^{\circ}$ 08: Axe 07: Organizational memory

We note that the averages are roughly with can meadows 2 (between 1,98 and 2,13) but with a deviation more or less high, that means the absence of organisational memory which makes it possible to store knowledge (tacit and explicit) and to re-use them at the good moment by the good person.

\subsubsection{Axe 08: Information and communication technologies}

\begin{tabular}{|l|c|c|c|c|c|}
\hline & N & Min & Max & Mean & Std. Deviation \\
\hline Information and communication technologies & 123 & 1 & 3 & 1.99 & .730 \\
\hline Contribution of the TIC/customer & 123 & 1 & 3 & 2.36 & .770 \\
\hline Contribution of TIC/KM & 123 & 1 & 3 & 2.24 & .782 \\
\hline Valid N (listwise) & 123 & & & & \\
\hline
\end{tabular}

Table $n^{\circ}$ 09: Axe 08: Information and communication technologies

We observe that the averages are more than 2, which means that the employees are conscious of the importance of new technologies of information and the communication in the organization, and who also contribute to the evolution of the organization and even the processes of the management of knowledge facilitate and support the training.

\section{Conclusion}

In an economy in permanent change, the perenniality and the prosperity of the organization depend on the permanent creation of knowledge in order to be more powerful, more competitive, more innovating and more reactive.

Therefore, the management of knowledge is a primordial function for the organization.

In this item, we tackled the question of the formalization of the management of knowledge in the managerial approach.

The management of knowledge is the process of creation, storage, share, use and evaluation of knowledge in the organization to improve their performance.

Algérie Télécom is the leader of telecommunications in the Algerian market. It provides telecommunication services such as the telephone and the Internet.

Indeed, there does not exist a service research and development $(R \& D)$ which guides the creation of new knowledge and consequently, in the firm, it does not have there an innovation concerning the development of the equipment. Therefore, it buys equipment to install them and use them.

The majority of the employees of DTT Tlemcen are generally academics, and that is due mainly to the activity of the organization which requires a certain qualification.

The organization does not have strategy of the management of knowledge, which resulted in encountering several problems such as the lack of information in some services and the overload in the others. Therefore, in spite of the existence of the information system, it is not effective or it does not function correctly. 
Thus, we noted a weak share of knowledge between the services and the units, which resulted in repeating the same errors, and the inexistence of the databases which store explicit knowledge in order to use them by the other services.

Moreover, there are not the devices which support the exchange of information and knowledge, and also the inexistence of a company's vision (common vision).

We also noted that there are not an organisational culture and a confidence between the employees and even the feeling of membership who support the division of knowledge because there' is a difference between the objectives of the management and waiting of the employees. Thus, we noticed the existence of the work group, but not the community of practice, because it does not imply the employees of the other units and even services.

In opposition, we noted that the leaders support the formation appropriatenesses.

On the other hand, we noted a lack of organisational memory and consequently the low availability of knowledge.

Lastly, the information and communication technologies play a central role in the improvement of the processes of the management of knowledge.

Therefore, starting from these results, we refuse the first assumption and we accept the second which says that in the managerial approach, the strategic management of knowledge is based on the combination between the processes of the management of knowledge, the personal and organisational factors as well as the contribution of technologies of information and communication.

Ultimately, it should be noted that the organization is in the train of restructuration to give more autonomy to its territorial managements in order to better managing the specific situations and to facilitate decision making to solve the problems encountered at the local level.

\section{References}

Alavi Maryam et Leidner Dorothy E, (2001), review: knowledge management and knowledge management systems: conceptual foundations and research issues, MIS Quarterly, Vol. 25, No. 1, March, pp. 107-136.

Aliouat Boualem, (2005), les conditions d'efficacité du « knowledge management » pour l'entreprise dans un contexte de croissance informationnelle: une analyse empirique de la gestion des connaissances, colloque international sur: l'économie de la connaissance, faculté des sciences économique et de gestion, université de Biskra, 12 et 13 Novembre, pp. 57-88.

Baudry Bernard, (2003), Economie de la firme, Edition la Découverte, Paris.

Barabel, M., Meier, O. et Teboul, T., (2008), Les fondamentaux du management, Dunod, Paris.

Benabou Djilali, (2008), Management des savoirs et développement des competences à l'heure des TIC, Thèse de doctorat en sciences de gestion encadrée par Bendiabdellah Abdeslam, Université Abou-Bakr Belkaid, Tlemcen, pp. 341.

Bordères Charles et Panisse Guy, (2003), Le management des connaissances au service du développement des compétences, Fiches techniques, La lettre du CEDIP-En lignes, No. 26, Juin, pp. 04, disponible sur le RICF (http//ricf.cedip.i2).

Byounggu Choi, (2002), Knowledge Management Enablers, Processes, and Organizational Performance: An Integration and Empirical Examination, thèse de doctorat encadrée par Heeseok Lee, the faculty of Korea Advanced Institute of Science and Technology, Seoul, Korea, 24 Mai, pp. 213.

CEN (Comité Européen de Normalisation), (2004), European Guide to good Practice in Knowledge Management - Part 1: Knowledge Management Framework, Mars, Brussels, pp. 33.

Dietrich Anne et Cazal Didier, (2003), gestion des compétences, savoirs tacites et production de connaissances, les cahiers de recherche (CLAREE) UPRESA-CNRS.

Dubois Nancy, Tricia Wilkerson, (2008), Gestion des connaissances : un document d'information pour le développement d'une stratégie de gestion des connaissances pour la santé publique, National Collaborating Centre for Methods and Tools, School of Nursing, Université McMaster, Hamilton, ON, pp. 74.

Faucher Jean-Baptiste P.L., Everett. André M and Lawson Rob, (2008), Reconstituting knowledge management, journal of knowledge management, Vol. 12, No. 3, pp. 3-16.

Fillol Charlotte, (2006), Apprentissage organisationnel et contexte organisationnel : une étude de cas chez EDF, XV ème Conférence Internationale de Management Stratégique, Annecy / Genève 13-16 juin, pp. 24.

Foray Dominique, (2004), l'économie de la connaissance, Casbah éditions, Alger, pp. 124.

Gaha Chiha, Mansour Nizar, La GRH comme levier du management des savoirs : cas de deux entreprises tunisiennes, pp. 1900-1917.

Gorelick carol, Tantawy-Monsou Brigitte, (2005), For performance through learning, knowledge management is the critical practice, The Learning Organization, Vol. 12 No. 2, pp. 125-139.

Guedda Chiraz, (2008), La fuite de connaissance comme un risque associé aux alliances et aux collaborations pour les jeunes firmes de biotechnologie, mémoire de maîtrise en administration des affaires, Université de Québec à Montréal, Janvier, pp. 127.

Hansen .Morten T, Nohria Nitin et Tierney Thomas, (2003), Quelle est votre stratégie de gestion du savoir ?, Le management du savoir en pratique, Harvard Business Review, éditions d'organisation, Paris, pp. 117-149. 
Hsia Tzyh-Lih, Lin Li-Min, Wu Jen-Her et Tsai Hsien-Tang, (2006), A framework For designing nursing knowledge management Systems, Interdisciplinary Journal of Information, knowledge, and Management, Vol. 1, pp. 13-22.

King, William R, (2009), Knowledge Management and Organizational Learning, Annals of Information Systems 4, Springer Science+Business Media, pp. 03-13.

Kipling Rudyard, (2007), Knowledge Management Framework for Government, National Institute for Smart Government, Hyderabad, INDIA, pp. 20.

Lakshman Chandrashekhar, (2009), Organizational knowledge leadership: An empirical examination of knowledge management by top executive leaders, Leadership \& Organization Development Journal, Vol. 30, No. 4, pp. 338-364.

Marchand Aude, (2005), Mettre en place une politique de capitalisation d'expériences : état des lieux et perspectives au Centre de Ressources Politique de la Ville en Essonne, mémoire de DESS en Sciences de l'information et de la documentation spécialisées, Institut National Des Techniques De La Documentation, Paris, 18 Octobre, pp. 135.

Nada K. Kakabadse, Kakabadse Andrew and Kouzmin Alexander, (2003) Reviewing the knowledge management literature: towards a taxonomy, journal of knowledge management, Vol. 7, No. 4, pp. 75-91.

Nevo Dorit, Brent Furneaux et Yair Wand, (2008), Towards an evaluation framework for knowledge management, Inf Technol Manage, Vol. 9, pp. 233-249.

NHS (National Library for Health: Specialist Library Knowledge Management) et De Brun Caroline, (2005), ABC of Knowledge Management, July, pp. 69, disponible dans l'internet on: http://www.library.nhs.uk/knowledgemanagement/.

Nonaka Ikujiro, Konno Noboru, (1998), The concept of « BA »: Building a Foundation for Knowledge Creation, California management review, Vol. 40, No. 3, pp. 40-54.

Oliver Stan et Kandadi Kondal Reddy, (2006), How to develop knowledge culture in organizations?, A multiple case study of large distributed organizations, journal of Knowledge Management, Vol. 10, No. 4, pp. 6-24.

Perrin Alexandre, La valorisation des pratiques de management des connaissances, outils de mesure et mesure des outils, pp. 27, km.typepad.com.

Prax. J-Y, (2003), le Manuel du knowledge management: une approche de 2e génération, Dunod, Paris, pp. 477.

Richard C. Hicks, Dattero Ronald and Galup. Stuart D, (2006), The five-tier knowledge management hierarchy, journal of knowledge management, Vol. 10, №. 1, pp. 19-31.

Rolland Nicolas, (2004), knowledge management impacts on decision making process, journal of knowledge management, Vol. 8, No. 1, pp. 20-31.

Rossion Françoise, (2008), Transfert des connaissances: stratégies, moyens d'action, solutions adaptées à votre organisation, Lavoisier, Paris, pp. 278.

Salim Juhana, Othman Mohd Shahizan et Zawani Sharhida, (2005), Integrated approach to knowledge management initiatives programme: towards designing an effective knowledge management system, International Conference on Knowledge Management, pp. 23.

Sammer Martin, Bornemann Manferd, Graggober Marion, Hartlieb Erich, Humpl Bernd, Koronakis Philipp, Primus Arthur, Ritsch Karl, Rollett Herwig, Tuppinger Josef, Willfort Reinhard, Wöls Kurt, (2003), An Illustrated Guide to Knowledge Management, Wissensmanagement Forum, Graz, Austria, pp. 43.

Sammour George, Schreurs Jeanne, Al-Zoubi A. Y et Vanhoof Koen, (2008), The role of knowledge management and e-learning in professional development, International Journal Of Knowledge and learning, Vol. 4, No. 5, pp. 465-477.

Simard Caroline et Rice Ronald E, The Practice Gap: Barriers to the Diffusion of Best Practices, pp. 87-123.

Yeh Ying-Jung, Lai Sun-Quae et Ho Chin-Tsang, (2006), Knowledge management enablers: a case study, Industrial Management \& data Systems, Vol. 106, No. 6, pp. 793-810. 